\title{
Substrate Specificity of Tissue Plasminogen Activator and Urokinase as Determined with Synthetic Chromogenic Substrates
}

\author{
Osamu Matsuo, ${ }^{*}$ Tetsuhiro SaKaI, ${ }^{*}$ Yasuo Takakura, ${ }^{* *}$ \\ and Hisashi MiHARA** \\ *Department of Physiology, Kinki University School of Medicine, \\ Minamikawachi-gun, Osaka, 589 Japan \\ **Department of Physiology, Miyazaki Medical College, \\ Miyazaki-gun, Miyazaki, 889-16 Japan
}

\begin{abstract}
Three different synthetic chromogenic substrates ( $H$-glutamylglycyl-L-arginine- $p$-nitroanilide (S-2227), pyro-glutamyl-glycyl-L-arginine$p$-nitroanilide (S-2444), and $H$-D-isoleucyl-L-prolyl-L-arginine- $p$-nitroanilide (S-2288)) were investigated for use in the measurement of plasminogen activator activity with high molecular weight urokinase (H-UK), low molecular weight urokinase (L-UK), and tissue plasminogen activator (TPA). The three substrates were hydrolyzed by both TPAtype and UK-type plasminogen activator. As regards the amidolytic activity of S-2227, TPA exhibited a weaker amidolytic activity, and L-UK a stronger activity. In the case of the amidolytic activity of S-2444, no great difference between the three activators was observed in terms of $V_{\max }$. As regards the amidolytic activity of S-2288, L-UK exhibited a stronger activity, and TPA a weaker activity. It is suggested that the molecular size of the synthetic chromogenic substrate was too small when compared to natural substrate (fibrin), and therefore that fibrin-binding sites around the catalytic site in TPA are not recognized.
\end{abstract}

Key Words: plasminogen activator, urokinase, tissue plasminogen activator, synthetic chromogenic substrate, kinetics.

Recent investigations on blood fibrinolysis have provided a new assay method as well as a new concept for plasminogen activation. Synthetic chromogenic tripeptides, having a similar aminoacid sequence to that of the natural substrate and coupled with $p$-nitroanilide, have been developed for the assay of plasminogen activator activity. When an enzyme cleaves the tripeptide-p-nitroanilide, free $p$-nitroaniline is released and its absorbance can be measured with a spectrophoto-

Received for publication April 5, 1983

* To whom correspondence should be addressed.

松尾 理, 酒井鉄博, 高倉保雄, 美原 恒 
meter at $405 \mathrm{~nm}$ (LiJNEN et al., 1980). Such synthetic substrates permit the measurement of fibrinolytic activity with higher accuracy and provide a practical, easy technique. Also, kinetic analysis becomes easier with such substrates when compared to conventional assays such as the fibrin lysis time method or fibrin plate method. Thus, synthetic substrates are now being employed not only for laboratory work but also for the measurement of fibrinolytic components in clinical samples.

According to the current concept of blood fibrinolysis, the fibrinolytic process is initiated on the surface of fibrin where fibrin-bound plasminogen and plasminogen activator react (WIMAN and CoLLEN, 1978). These three components form a "tripod" complex: plasminogen activator-plasminogen-fibrin, and this tripod complex enhances fibrinolysis (lysis of fibrin) in a burst (HoYlaERTs et al., 1982). On the other hand, when plasminogen activator activates the plasminogen in the plasma, the plasmin produced is inactivated instantaneously by $\alpha_{2}$-antiplasmin ( $\alpha_{2}$-plasmin inhibitor). Excess plasmin then digests the fibrinogen, leading to a hemorrhagic tendency. Thus, the physiological role of fibrinolysis is realized mainly on the fibrin surface (solid phase) and not in the plasma (liquid phase) (MATSUO, 1981). Recently, a new type of plasminogen activator which is immunologically and biologically different from the urinary plasminogen activator, urokinase (UK), has become available for the treatment of thromboembolism; that is, tissue plasminogen activator (TPA) (MATSUO et al., 1981; WEIMER et al., 1981; PenNiCA et al., 1983). TPA induces fibrinolysis and not fibrinogenolysis, while UK causes fibrinogenolysis to a far greater extent than fibrinolysis (MATSUO et al., 1982).

Plasminogen activators are therefore now classified into two types: the TPA type and the UK type. For the measurement of plasminogen activator activity, three chromogenic substrates have been synthesized: $H$-glutamyl-glycyl-L-arginine$p$-nitroanilide (S-2227), pyro-glutamyl-glycyl-L-arginine- $p$-nitroanilide (S-2444), and $H$-D-isoleucyl-L-prolyl-L-arginine- $p$-nitroanilide (S-2288). The present study was undertaken to investigate the spectrum of substrate hydrolysis for each plasminogen activator. The three synthetic substrates, S-2227, S-2444, and S-2288, were investigated as to whether each plasminogen activator could discriminate each substrate.

\section{MATERIALS AND METHODS}

The following materials were purchased: S-2227 ( $H$-glutamyl-glycyl-L-arginine-p-nitroanilide-dihydrochloride) (KABI, Stockholm), S-2444 (pyro-glutamylglycyl-L-arginine-p-nitroanilide-dihydrochloride) (KABI, Stockholm), and S-2288 ( $H$-D-isoleucyl-L-prolyl-L-arginine- $p$-nitroanilide-dihydrochloride) (KABI, Stockholm). Two kinds of urinary plasminogen activators, high molecular weight urokinase (H-UK) (MW 53,000) and low molecular weight urokinase (L-UK) 
(MW 33,000), were purified showing a single band on SDS gel electrophoresis. Tissue plasminogen activator (TPA) was partially purified from the culture medium of a melanoma (RIJKen and Collen, 1981).

Determinations of amidolytic activity were carried out as follows. For S2227 and S-2444, $300 \mu \mathrm{l}$ of buffer, $100 \mu \mathrm{l}$ of plasminogen activator solution, and $50 \mu \mathrm{l}$ of the substrate were mixed in a micro-cell at $37^{\circ} \mathrm{C}$ in a double-beam photometer (Hitachi 202) and the increase in optical density at $405 \mathrm{~nm}$ was recorded. For S-2288, $200 \mu \mathrm{l}$ of buffer, $200 \mu \mathrm{l}$ of plasminogen activator solution, and $200 \mu \mathrm{l}$ of the substrate were mixed and the increase in optical density was measured. The buffers used in the present study were $500 \mathrm{~mm}$ Tris (tris(hydroxymethyl)aminomethane) hydrochloride buffer, $\mathrm{pH} 9.0 ; 50 \mathrm{~mm}$ Tris hydrochloride buffer, $\mathrm{pH}$ 8.8; $100 \mathrm{~mm}$ Tris hydrochloride buffer, $\mathrm{pH}$ 8.4. The differences in buffer did not give rise to any significant difference in substrate hydrolysis. The $\mathrm{pH}$ optimum of chromogenic substrate was broad (CLAESON et al., 1978). The plasminogen activator was dissolved in each of the buffer solutions. The plasminogen activator activity of TPA was expressed in International Units, i.e. the enzyme unit of urokinase, and adjusted to $1,000 \mathrm{IU} / \mathrm{ml}$. The substrate was dissolved in distilled water and the following six concentrations were used: $3,1,0.5,0.4,0.25$, and $0.2 \mathrm{~mm}$. The molar extinction coefficient of $p$-nitroaniline was 9,905 at $405 \mathrm{~nm}$. $K_{\mathrm{m}}$ and $V_{\max }$ were obtained from Lineweaver-Burk plots.

\section{RESULTS}

\section{S-2227 amidolytic activity}

The three different plasminogen activators (high molecular weight urinary plasminogen activator (H-UK), low molecular weight urinary plasminogen activator (L-UK), and tissue plasminogen activator (TPA)) catalyzed S-2227. However, there was some difference in amidolytic activity among the activators. TPA exhibited a weaker amidolytic activity, and L-UK a stronger activity. The $V_{\max }$ of TPA was about 40 times smaller than that of L-UK. The $K_{\mathrm{m}}$ value was the smallest in the case of TPA (Table 1). An example of the results is shown in Fig. 1 which gives a Lineweaver-Burk plot of the data.

\section{S-2444 amidolytic activity}

The three plasminogen activator solutions used in this study showed S-2444 amidolytic activity. As regards $V_{\max }$, there was no great difference among the three activators, which was in contrast to S-2227. However, there was a wide variation in $K_{\mathrm{m}}$ value, the $K_{\mathrm{m}}$ value being the smallest in the case of H-UK, and that of TPA being 15 times larger than that of H-UK (Table 1). An example of the results is shown in Fig. 2 as a Lineweaver-Burk plot.

\section{S-2288 amidolytic activity}

The three plasminogen activator solutions lyzed S-2288, but there was some 
Table 1. Kinetic parameters of H-UK, L-UK, and TPA with respect to S-2227, S-2444, and S-2288.

\begin{tabular}{lccccccc} 
& \multicolumn{3}{c}{$K_{\text {m }}(\mathrm{mol})$} & & \multicolumn{3}{c}{$V_{\max }(\mathrm{mol} / \mathrm{min})$} \\
\cline { 2 - 3 } \cline { 6 - 8 } & $\mathrm{S}-2227$ & $\mathrm{~S}-2444$ & $\mathrm{~S}-2288$ & & $\mathrm{~S}-2227$ & $\mathrm{~S}-2444$ & $\mathrm{~S}-2288$ \\
\hline H-UK & $2.0 \times 10^{-3}$ & $\mathbf{0 . 5 3 \times 1 0 ^ { - 3 }}$ & $\mathbf{0 . 8} 8 \times 10^{-3}$ & & $1.4 \times 10^{-8}$ & $1.9 \times 10^{-8}$ & $2.6 \times 10^{-8}$ \\
L-UK & $3.2 \times 10^{-3}$ & $0.94 \times 10^{-8}$ & $1.1 \times 10^{-3}$ & & $2.6 \times 10^{-8}$ & $2.8 \times 10^{-8}$ & $4.2 \times 10^{-8}$ \\
TPA & $1.4 \times 10^{-3}$ & $8.01 \times 10^{-3}$ & $2.3 \times 10^{-3}$ & & $6.3 \times 10^{-10}$ & $2.5 \times 10^{-8}$ & $1.1 \times 10^{-8}$ \\
\hline
\end{tabular}

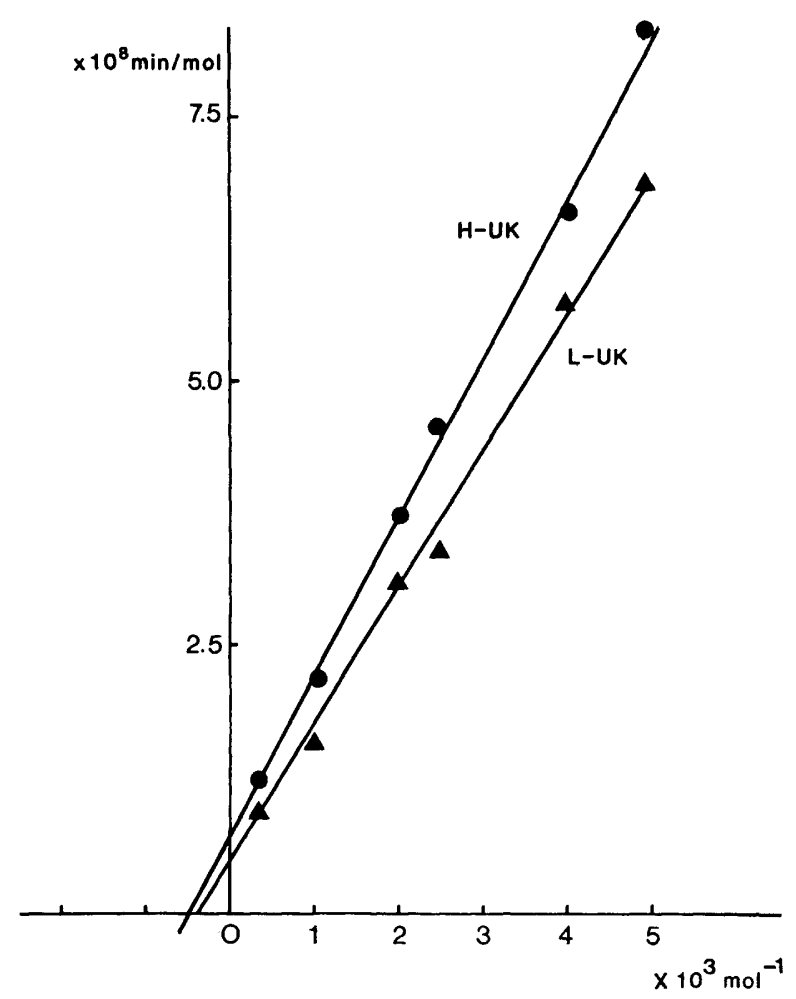

Fig. 1. Amidolysis of S-2227 with H-UK and L-UK (Lineweaver-Burk plot). Ordinate, reciprocal value of amidolytic velocity; abscissa, reciprocal value of substrate concentration. The straight line was obtained by the method of least squares.

difference in the degree of amidolytic activity among them. L-UK exhibited a stronger activity, and TPA a weaker activity. The $K_{\mathrm{m}}$ value was the smallest in the case of H-UK, with that of TPA being almost 3 times larger than that of H-UK (Table 1). The $V_{\max }$ of L-UK was about 4 times larger than that of TPA. An example of the results is shown in Fig. 3 as a Lineweaver-Burk plot. 


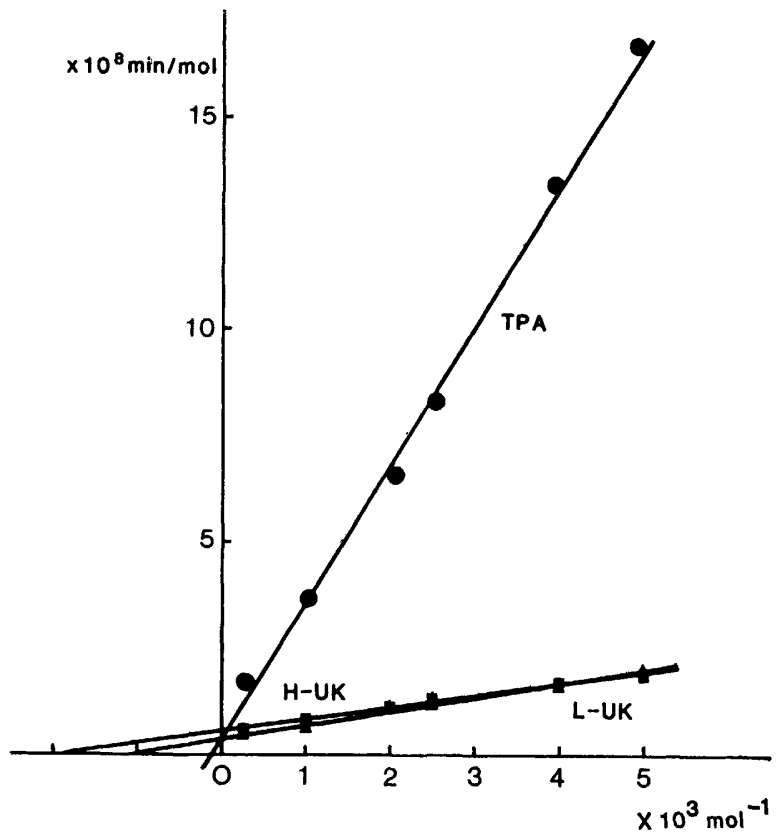

Fig. 2. Amidolysis of S-2444 with H-UK,[L-UK,/and TPA (Lineweaver-Burk】plot). Ordinate and abscissa as in Fig. 1.

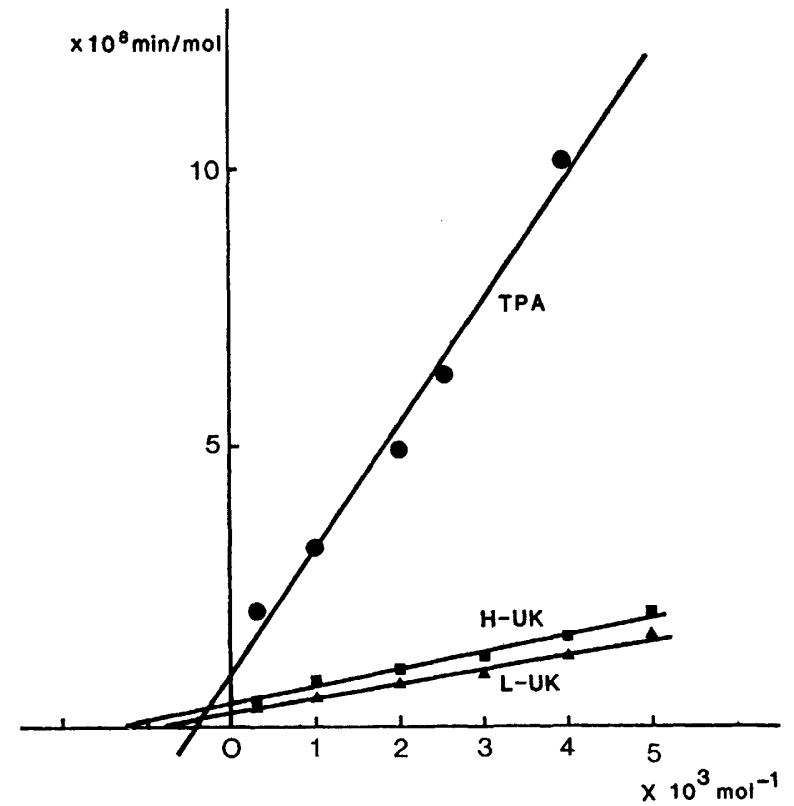

Fig. 3. Amidolysis of S-2288 with H-UK, L-UK, and TPA (Lineweaver-Burk plot). Ordinate and abscissa as in Fig. 1. 


\section{DISCUSSION}

Recent advances in blood fibrinolysis have clarified that tissue plasminogen activator (TPA) induces fibrinolysis mainly on the fibrin surface, while the urinary plasminogen activator, urokinase (UK), induces fibrinogenolysis in the fluid (plasma). TPA is different from UK immunologically and biochemically (molecular weight and primary structure). It is thus considered better to classify the plasminogen activators into two types: the TPA type and the UK type. Although several synthetic chromogenic substrates are now available for the measurement of plasminogen activator, the substrate specificity for each plasminogen activator remains unclear.

In the present study, three different synthetic chromogenic substrates (S2227, S-2444, and S-2288) were employed as a substrate for three different plasminogen activators. As summarized in Table 1, the value of $K_{\mathrm{m}}$ for S-2227 was the smallest for TPA $\left(1.4 \times 10^{-3} \mathrm{~mol}\right)$; the smallest value of $K_{\mathrm{m}}$ for S-2444 was observed with H-UK $\left(0.53 \times 10^{-3} \mathrm{~mol}\right)$; and the smallest value of $K_{\mathrm{m}}$ for S-2288 was also obtained with H-UK $\left(0.8 \times 10^{-3} \mathrm{~mol}\right)$. Concerning the $V_{\max }$ values of S2227 , the largest was observed with L-UK $\left(2.6 \times 10^{-8} \mathrm{~mol} / \mathrm{min}\right)$; the value of $V_{\max }$ for S-2444 was the largest with L-UK $\left(2.8 \times 10^{-8} \mathrm{~mol} / \mathrm{min}\right)$; and the largest $V_{\max }$ of S-2288 was also obtained with L-UK $\left(4.2 \times 10^{-8} \mathrm{~mol} / \mathrm{min}\right)$.

S-2227 was first developed as a synthetic chromogenic substrate for plasminogen activator, and its specificity to plasminogen activator was claimed previously (FrIBERGER, 1979). S-2444 was the second substrate synthesized for plasminogen activator, especially for urokinase. The results of the present study showed the largest $V_{\max }$ value with L-UK (Table 1). However, TPA lyzed S-2444 almost identically to L-UK. It is not possible therefore to distinguish TPA-type plasminogen activator from UK using this substrate. S-2288 was the third substrate for plasminogen activator, especially TPA-type activator. However, as shown in Table 1, the kinetic parameters revealed that S-2288 is not specific to TPA, but UK hydrolyzes S-2288 well.

In the present study, the spectrum of substrate specificity was thus examined using three plasminogen activators. However, both TPA-type and UK-type plasminogen activators hydrolyze synthetic chromogenic substrates well. In other words, as regards amidolytic activity, there was no great difference between TPA-type and UK-type plasminogen activator. On the other hand, when the natural substrate (fibrin) was employed, TPA showed stronger fibrinolytic activity, but UK, lesser activity (MATsuo et al., 1981). These results indicate that TPA has fibrin-binding sites, which recognize fibrin (natural substrate). However, synthetic chromogenic substrate which has a similar aminoacid sequence to the natural substrate, is too small to be recognized by the enzyme.

This work was supported in part by a research grant from the Protein and Nucleic Acid Research Association (No. 3). 


\section{REFERENCES}

Claeson, G., Friberger, P., Knös, M., and Eriksson, E. (1978) Methods for determination of prekallikrein in plasma, glandular kallikrein and urokinase. Haemostasis, 7: 76-78.

FrIBERger, P. (1979) AB Kabi Peptide Research, Mölndal.

Hoylaerts, M., Rijken, D. C., Lijnen, H. R., and Collen, D. (1982) Kinetics of the activation of plasminogen activator. J. Biol. Chem., 257: 2912-2919.

Lijnen, H. R., Collen, D., and Verstraete, M. (1980) Synthetic substrates in clinical blood coagulation assays. In: Developments in Hematology, Vol. 1, Martinus Nijhoff Publishers, The Hague, pp. 3-141.

Matsuo, O. (1981) Approach to the third generation of thrombolytic agents. Nihon Iji Shinpo, 2999: 43-46.

Matsuo, O., Nishida, Y., Akazawa, K., and Mihara, H. (1982) Effect of urokinase on fibrinolysis and fibrinogenolysis. Jpn. J. Physiol., 32: 879-883.

Matsuo, O., Rijken, D. C., and Collen, D. (1981) Thrombolysis by human tissue plasminogen activator and urokinase in rabbits with experimental pulmonary embolus. Nature, 291: 590-591.

Pennica, D., Holmes, W. E., Kohr, W. J., Harkins, R. N., Vehar, G. A., Ward, C. A., Bennet, W. F., Yelverton, E., Seeburg, P. H., Heyneker, H. L., Goeddel, D. V., and Collen, D. (1983) Cloning and expression of human tissue-type plasminogen activator cDNA in E. coli. Nature, 301: 214-221.

RIJKeN, D. C. and Collen, D. (1981) Purification and characterization of the plasminogen activator secreted by human melanoma cells in culture. J. Biol. Chem., 256: 7035-7041.

Weimer, W., Stibbe, J., Van Seyen, A. J., Billiau, A., De Somer, J., and Collen, D. (1981) Specific lysis of an iliofemoral thrombus by administration of extrinsic (tissue-type) plasminogen activator. Lancet, ii: 1018-1020.

Wiman, B. and Collen, D. (1978) Molecular mechanism of physiological fibrinolysis. Nature, 272: $549-550$. 